\title{
The future prospects of electronic seed lists
}

\author{
L. J. W. van den Wollenberg
}

Received: 21 August 2009/Accepted: 23 December 2010/Published online: 8 January 2011

(C) Springer Science+Business Media B.V. 2011

\begin{abstract}
For many botanic gardens worldwide, seed lists have provided a cost-effective means to replace plant losses in their collections for many decades, if not centuries. In seed lists, seeds are offered on the basis of what each garden can manage to collect and considers 'of interest' to other botanic gardens, some offering relatively few, while others offer many, or only wild collected seeds. Seed lists have always been printed on paper. With the use of printed seed lists, the amount of information per accession has always been quite limited to keep printing costs low. Over the past few years, electronic seed lists have been rapidly replacing printed seed lists. Since distribution is electronic, there is no longer a direct link between the amount of information provided and the cost per seed list sent out. This now offers new opportunities to share information that is linked to the plant material that botanic gardens exchange. Information is not limited to text, as images can also be included. This situation is beneficial if seed-raised plants are to be used for in situ conservation. Electronic seed lists have other advantages, but there are also some disadvantages. e.g., electronic information offered via websites is quite ephemeral in nature. Some suggestions are made to overcome the several drawbacks.
\end{abstract}

Keywords Botanic garden · Collection · Conservation · Index seminum · Information exchange $\cdot$ IPEN number

\section{Introduction}

Botanic gardens throughout the world have showcased global plant diversity for decades if not centuries. Today, showcasing the world's plant diversity is ever more important in order to gain public support for plant conservation. Plant collections, as maintained in botanic gardens, can be used to raise awareness and concern through education and public information. Botanic gardens are known to maintain species that have gone extinct in the wild, e.g. Sophora toromiro (Lobin and Barthott 1988). Detailed information on the wild

L. J. W. van den Wollenberg ( $₫)$

Botanic Garden, Biotechnology Department, Delft University of Technology, Julianalaan 67,

2628 BC Delft, The Netherlands

e-mail: 1.j.w.vandenwollenberg@tudelft.nl 
origin of plant material is vital if it is to be used for reintroduction to the wild. When few populations remain, the use of ex situ specimens may be an option. However, in such cases, a sufficiently wide gene pool is vital, and for this, plants of known wild origin are a must. BGCI has published The Darwin Technical Manual for Botanic Gardens, in which the information needs are listed (Leadley and Greene 1998).

Botanic gardens have been exchanging plants in the form of seeds for centuries, to expand their collections for the purpose of research or education, or as ornamentals, and to replace the inevitable losses that occur in any living plant collection. The Index Seminum or seed list has been used for centuries for this purpose. Before that, catalogues of plant collections were produced and distributed, and may have been used for the same purpose.

For instance, the oldest printed seed list issued by the Hortus Botanicus Utrecht dates back to 1796, and they have also kept the seed lists they received from other gardens, from 1838 onwards. For 1838, the Indices Seminum of 29 botanic gardens were received (H Persoon, personal communication, 2009). The gardens that have consistently archived the seed lists which they received, have realised their importance for reference purposes.

This reference purpose has become more significant in the last decades of the twentieth century, as the focus grew on the importance of known wild origin of plants in collections for genetic research and conservation purposes. With both developments, the provenance of material has become increasingly important (Cullen 2004).

At the same time, however, botanic gardens and other botanic institutions have been facing working budget reductions, leading to both staff and working budget reduction. Financial considerations have most likely been the cause of reduction in size of the printed seed lists, achieved both by reduction of items offered, as well as reduction of relevant data provided. Printing and postage costs could thus be reduced. However, this has negatively affected the availability of wild origin details that are so important for wild-collected species.

While an increase in interest regarding wild collected species could be noted, the provision of the relevant data sets was adversely affected by budget considerations. It remains unclear if these relevant data are recorded, or whether they simply do not make it onto the seed list. Since seed lists were and still are the main source for new plants in botanic garden collections, the inadequacies in data provision have affected the potential usefulness of such wild collected plants for conservation purposes (Badley et al. 2004), and throughout.

With the development of the internet, the number of printed seed lists is rapidly declining in favour of electronic seed lists. From the end of 2008 to mid 2009, the Botanic garden of Delft University of Technology received 82 electronic seed list, over $25 \%$ of the total number of seed lists received annually. Electronic seed lists have many obvious advantages. Given these advantages in comparison with printed seed lists, the latter is likely to disappear altogether in the next decade or so.

Electronic seed lists come in two basic forms:

- Seed list as an attached file sent directly by email or as a download from a home page

- Seed list available on-line (with or without online ordering) and email notification upon publication of the seed list

A combination of these two is also often encountered.

\section{Advantages of electronic seed lists}

1. Cost effectiveness: there are no printing costs, nor postage costs; merely the costs of the internet connection, and possibly of the amount of data sent. 
2. Speedy delivery: there are no delays in delivery due to shipping and schedules of the postal service. Every garden on the list receives the seed list or notification at the same time, irrespective of geographical distance.

3. Much more information: the amount of information is not subject to limits in order to reduce cost. Apart from the importance of wild origin data, information can be added about identification, relevant literature, or particular cultivation requirements for difficult-to-grow species (Given 1987). A recent study revealed that data availability in seed lists associated with wild collected plants is disappointing (Aplin et al. 2007);

4. Not limited to text only: images of the plant material, noteworthy details (e.g. for identification) and links to specific information on the web can now also be included, thereby opening up new opportunities for more complete information dissemination. Such images can help to quickly determine if something other than the taxa requested germinates in the seed pots.

5. Relevant information can be recorded efficiently by the receiving garden. Information from seed lists can be copied and pasted instead of hand-typing it into your database. With printed seed lists, the increased data, if provided in the printed seed list, also meant that more data had to be typed in, which slowed down the seed registration process. The cut-and-paste option in electronic seed lists already saves much time. Modern data systems can also include the seed list files, linked to the relations records.

6. Use of the International Transfer Format (ITF, v. $1 \&$ 2) for importation of data can save even more time. For this, the botanic garden offering the seeds needs to take the trouble to generate an ITF-file of the seed list issued. Some gardens, e.g. Utrecht University Botanic gardens, are already doing this.

7. Ephemeral seeds can also be offered directly as an addition to the seed list at any given moment when the seeds become available, after the main seed list has already been distributed.

8. The widespread use of electronic seed lists also opens up new and powerful possibilities. E.g. a European electronic seeds search through all electronic seed lists accessible through the internet can now be organised. All that is needed is an agreed key word to be included in the seed list somewhere, and the electronic seed list needs to be accessible on searchable web pages. E.g., the keyword for the winter 2008/2009 was "ebgconsortiumindexseminum2009". Each year, the appropriate year replaces 2009. For EUROGARD V, Matthew Jebb produced a poster "A Pan-European seedlist search system" on behalf of the EU Botanic Gardens Consortium (Jebb 2009).

9. Electronic seed lists are more environmentally-friendly, they do not require paper, ink, or physical transport. The format that is based on online ordering is the most environmentally-friendly form.

10. Production of the seed list in-house is easier, since no Multi Media Service is necessary for layout, which also saves time.

11. The storage of electronic seed lists is much easier, since no (expensive) storage space is required, as is the case with printed seed lists.

12. The increased use of electronic seeds lists will inevitably also encourage the use of a computer to document collections, where this is not common practice yet. This will potentially enable a more complete assessment of all ex situ plants worldwide when these gardens also upload their plant data to the Plant Search Database of Botanic Gardens Conservation International (http://www.bgci.org/plant_search.php). 
A good example is Utrecht University Botanic Gardens (www.bio.uu.nl/bottuinen/). The seed list page provides access to:

- the web-version of the seed list with images of the accessions of the species offered;

- a downloadable version (pdf-format);

- and an ITF text file for a complete data set of each accession on the latest seed list.

In short, electronic seed lists have many advantages, and not in the least, they allow a botanic garden to save much time and money.

It is not all positive, however. With all the obvious advantages, it is easy to overlook that there are also disadvantages.

\section{Disadvantages}

1. Changes of email addresses and web-urls: urls can become void when websites are moved to another provider, and seed lists then become inaccessible. Private users easily change providers to obtain better deals, and this happens with botanic gardens as well, although fortunately less frequently. With the increased use of electronic distribution lists, if a particular botanic garden changes provider, all the other botanic gardens that that garden has a relation with, need to change the email address, so they need to be informed. Such changes inevitably cause loss in contacts, and distribution lists containing invalid email addresses. This means that changes in email addresses are best avoided altogether. Stability in contact details (including email and website addresses), is of increasing importance.

2. Electronic seed lists can be very ephemeral: on the recipients side, the "delete"-button can too easily discard emailed seed list files. On the provider-side, in the case of online seed lists, the non-downloadable (and downloadable) versions are lost when the botanic garden removes the seed list after the seed list season.

In both cases, this is particularly unpleasant in case of delayed registration (e.g. when the seeds are received after the seed sowing season, or when other priorities necessitate delay of registration. Often the seeds are then stored until the new seed sowing season commences, by which time the data may no longer be available. The removal of the online seed list, or the loss of downloaded seed lists, both constitute a loss of information, which can only be countered by contacting the providing garden for the details.

In this day and age, where automation of information exchange brings benefits to all users, individual requests for information are often not granted (Wolfram Lobin, personal communication).

3. Limited size for email attachments: many providers set a limit to the size of an email and its attachment, e.g. $4 \mathrm{Mb}$. Seed lists sent out by email are thus limited in size. This may mean a new constraint in the amount of information provided. Online seed lists suffer much less from such constraints, and downloadable seed lists can also be much larger since the File Transfer Protocol (FTP) allows much bigger downloads.

4. Where the printed seed lists require only a pen, an envelope and some stamps, the electronic seed list requires a computer, internet access (provider), preferably high speed ADSL, etc. This also means that ordering needs to be done from behind a computer, unless the received seed lists are printed (with the adverse environmental effect), or moved onto a PDA or netbook. 
5. Detailed geographical information on the whereabouts of populations of threatened species, especially on publicly available websites and seed lists, may have the unwanted side effect of over-collecting by irresponsible individuals. The danger of the information age is that everything is available from the internet, including sensitive information such as precise location data of rare and threatened species. For those species where over-collecting is a real threat (orchids, cacti, ornamental species), this is acutely problematic. But in other cases, the rarity of species also attracts collectors.

6. When the seed list is uploaded to the garden website rather than distributed via email, knowledge of (editing) the garden web pages may become a new requirement.

7. In case of botanic gardens, solely with older staff, unfamiliar with computers and electronic documents, the increased use of electronic seed lists may lead to their reduced access to seed lists.

\section{How can electronic seed lists support the conservation work of botanic gardens in the age of climate change?}

It is becoming clear that we are facing a changing climate. While bioclimatic models for the effect of climate change on plants are being developed, these still need further development (Hawkins et al. 2008). The last completed global assessment dates back to 1998 (Walter and Gillett 1998) and lists almost 34,000 species as being threatened to various extents. However, it is not difficult to foresee that currently threatened species will further decline, as climate change will most likely have a negative effect on their survival. This means that the average threat level will increase, so the number of critically endangered plant species will also increase, and currently already critically endangered species are more likely to go extinct.

This means that threatened plants in collections become more important. Of those threatened species, especially when wild collected species or their offspring are offered in seed lists, the wild origin data should always accompany the seeds.

Plant material from ex situ origin with known wild origin data could be used for the establishment of new populations (including assisted migration) and reintroduction. In such cases, assessment of the genetic variation of the plant material to be used is of major significance. While it would be best to use seeds specifically collected for conservation purposes from remaining wild populations, using the appropriate protocols to catch all the genetic variation still present in the wild populations, and stored in seed banks, this may no longer be possible, and then plant material (plants, cuttings or seeds) drawn from living plant collections remain the only option.

With the above in mind, proper and complete documentation of wild collected seeds offered in seed lists is of prime importance for future conservation action (Cullen 2004). This is not limited to threatened species lists as they now stand, since climate change may result in many more plant species becoming threatened (Gran Canaria Group 2006). The documentation is the basis to separate the different wild origins of seeds or plants of a particular species. In this respect, the Convention on Biological Diversity (1993), and the, so far largely, European response of botanic gardens may prove helpful. The International Plant Exchange Network (IPEN) was established for the non-commercial exchange of plant material (mostly seeds) between botanic gardens. In order to comply with the CBD requirement of tracking of germplasm exchange, the IPEN number was introduced, consisting of four parts. The first part is the country-of-origin code (2-digit code). The second 
part indicates the presence or absence of restrictions for further dissemination (1 or 0 respectively). The third part is the code of the botanic garden that introduced the plant material into the IPEN network, and the fourth part is the accession number of the aforementioned garden.

This IPEN code uniquely identifies germplasm and distinguishes germplasm of different origins of the same species. The IPEN code is increasingly provided in the seed lists of the member gardens. The IPEN number will thereby contribute significantly to the conservation of currently threatened plant species, and those plant species that will become threatened due to climate change, or other adverse developments. This is another reason to embrace IPEN and the use of IPEN numbers.

\section{What changes are necessary for conservation to profit from electronic seed lists?}

Electronic seed lists can help conservation, if:

- more complete datasets can be offered, including images, tables, etc.

- upon further distribution, these complete datasets can be easily and accurately transferred with the seeds;

- different origins of plant accessions of a given species can be easily identified;

- adequate recording of the IPEN number that comes with seeds if provided is common practice: and issue of an IPEN number by a botanic garden if no IPEN number is as yet attached to a seed sample;

- botanic gardens, that by themselves do not run conservation programmes but restrict their activities to ornamental display and education, can improve the quality of documentation of their collections, thereby revealing those plants which are of known wild origin, thus expanding the global pool of plants potentially useful for conservation purposes;

- threatened taxa on the list are clearly marked, perhaps in a separate section, and the recipient is invited to join conservation projects or conservation research.

\section{Recommendations for electronic seed lists}

1. As soon as possible issue an electronic seed list instead of a printed one. It protects the environment, is cheaper and saves time;

2. Format: the most environmental friendly format is an online seed list with online ordering. The online seed list with online ordering in the form of a special web page with click boxes for ordering is more complicated to produce than an electronic seed list sent out as an email attachment, in a file format such as a Word file or a PDF file. In case of an online seed list with online ordering, a downloadable version should also be maintained on the website, for future reference purposes;

3. If you send out electronic seed lists by email, limit the electronic size to prevent providers from blocking it. And don't forget to include your address and contact details: on more than one occasion, this is forgotten, rendering the seed list virtually useless unless the email can be retraced;

4. As for the electronic seed lists you receive: try not to print these, for the environmental gain is then partly lost; 
5. Make available all relevant details of seeds offered. This can either be within the seed list, or within a separate ITF file or other information file, e.g. as is done by Utrecht University Botanic gardens (Fig. 1). If available, also provide images and other illustrations relating to the accession offered (Fig. 2). Provision of such information as

\section{Index Seminum Downloads}

The web based format (html) has been created directly from Atlantis BG database, using the Seed List report. It has the advantage of having many pictures of the accessions. It is only temporarily available (until next Seed List takes its place).

Additional we provide the Index Seminum in 2 different digital formats, for printing and future reference:

- Acrobat PDF format (ca. $2 \mathrm{Mb}$, identical to the hard copy and you can store or print it if you like)

- ITF2 Ansi Text (ca. $120 \mathrm{~Kb}$ ) file format: this includes all ITF2 fields and includes much more information about verification, Taxa, Donor information, Literature etc. (this will be ideally the standard format for accession data exchange and already can be handled automatically by some databases like Atlantis Botanic Garden, for more information please contact us).

Fig. 1 Apart from the web-based format, at Utrecht University Botanic Gardens, a downloadable version of the seed list is available in PDF-format, as well as the accompanying data in ITF-2 format

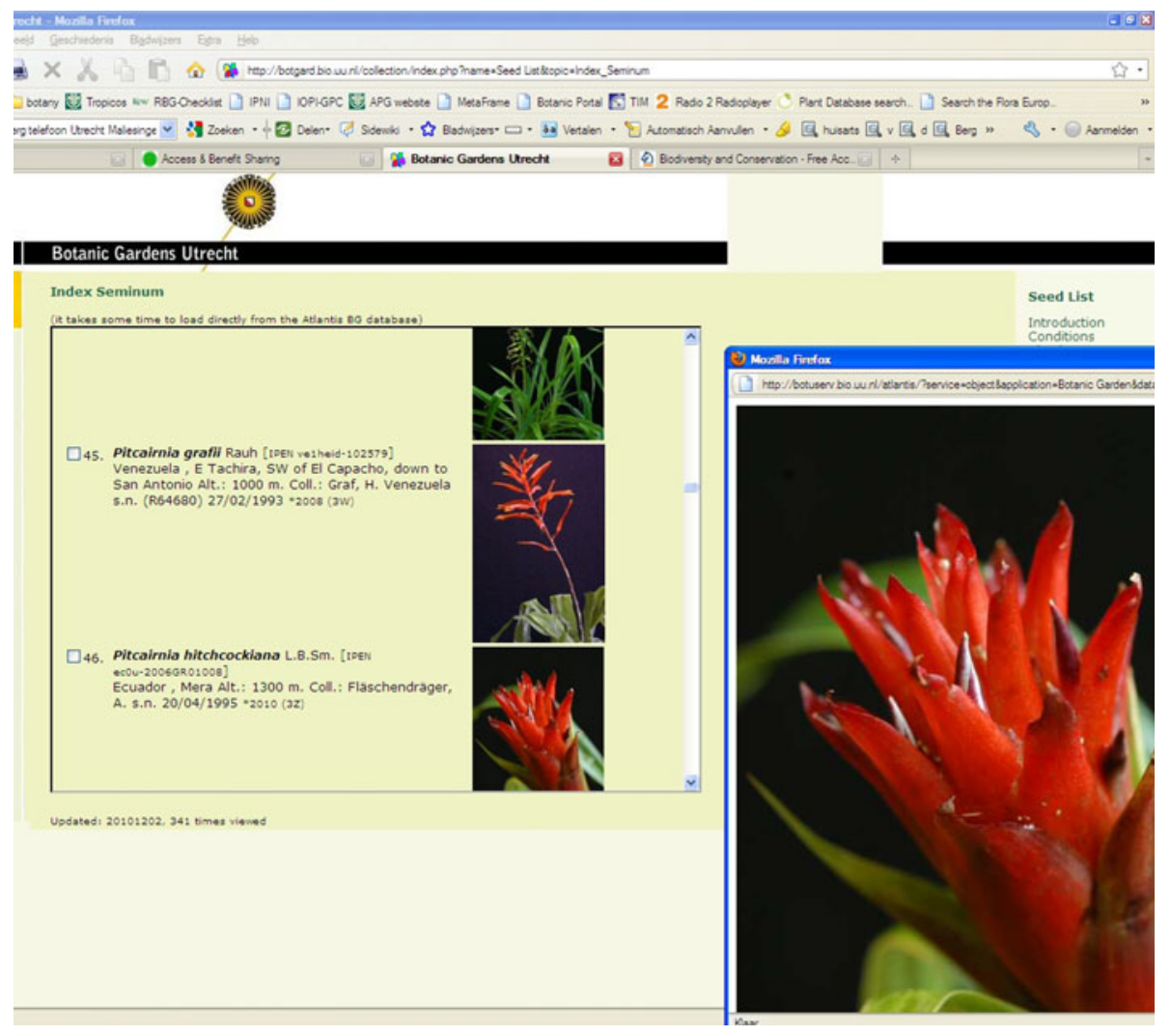

Fig. 2 The web-based seed list of Utrecht University Botanic Gardens contains thumbnails as well as higher resolution images (available by clicking the thumbnail) Since these images are of the plants of which seeds are offered, this is helpful in documenting the received plant material, and makes it easier to check whether the developing plants are actually what they should be 
a standard procedure when issuing a new seed list is much more efficient compared to answering requests for details later. Collections databases are increasingly accessible through the internet. e.g. the Thematis Botanic Portal (www.thematis.nl/botanicportal/; Figs. 3, 4), which currently allows searching of the collections of Amsterdam, Delft and Utrecht. These gardens use Thematis software to jointly provide access to their databases. Web access of collections databases is still not widely installed, and even then, searching for individual accession data is much more time-consuming that extracting data from a seed list or ITF data file;

6. Send sensitive information of threatened wild populations to trusted colleagues only;

7. Do not change your gardens email address or website url. Reliance on electronic distribution lists (for seed lists or seed list notifications) becomes very important, and with this, stability of email addresses;

8. Develop a policy on safe storage of electronic seed lists received from other gardens for future reference. This is obvious for printed seed lists, because they will otherwise pile up on desks. Electronic seed lists can be spread over many file folders and stay unnoticed, unless an archiving policy is agreed;

9. Help the development of the global seed search system by including the key word "ebgconsortiumindexseminumyear" in your electronic seed list and make it accessible on a website ("year" is the 4-digit year: for details see www.plantnetwork.org/ebg/).

Smart use of electronic seed lists will both improve the quality and volume of the data, as well as efficiency of the accessioning process. It will also be instrumental in increasing the

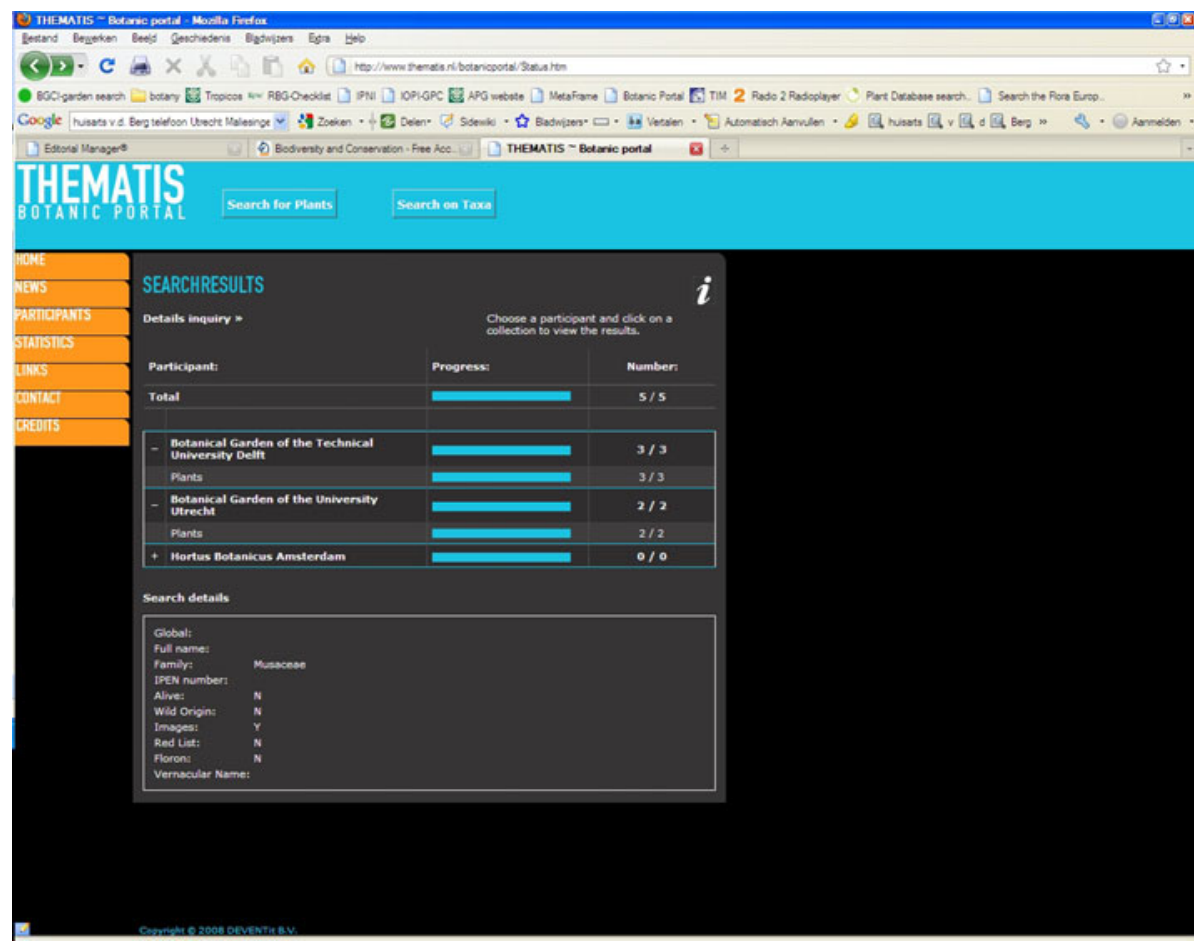

Fig. 3 The Thematis Botanic Portal allows searching all linked online databases at the same time. In this example, illustrations of Musa were searched 


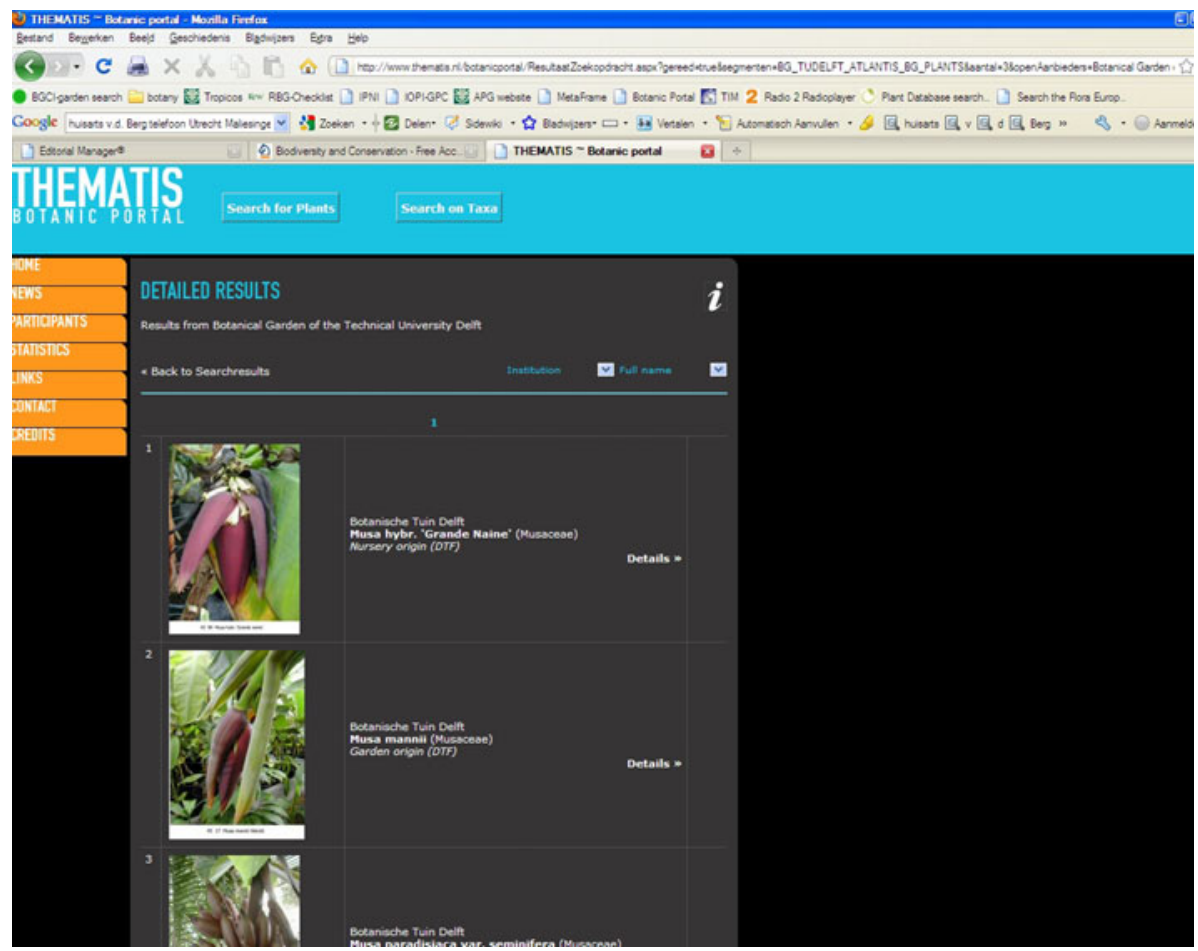

Fig. 4 Musa images from the Atlantis Plant Database, Botanic Garden, Delft University of Technology

use of wild collected plants for conservation purposes. Most databases can easily be adapted to accommodate the small changes necessary, such as recording of the IPEN number, and linking of the seed lists to relations records.

With the emergence of electronic seed lists, it now becomes much more feasible to establish a global or regional repository for seed lists. This could finally emanate in a periodic survey of seeds offered worldwide. One of the criticisms on seed lists has been that quite often the same seeds are offered by many botanic gardens, but in the absence of an annual global overview of seeds offered by botanic gardens across the globe, it remains difficult for botanic gardens to assess to what extent they were contributing to this undesirable situation. An overview of what is annually offered by botanic gardens worldwide would help botanic gardens to review their policy regarding what they should offer.

\section{References}

Aplin D, Linington S, Rammeloo J (2007) Indices seminum: are they really worth the effort? Sibbaldia 5:93-107

Badley C, Hill D, Wray N (2004) Inadequate accession data compromises the conservation value of plant collections. Sibbaldia 2:5-20

Convention on Biological Diversity (1993) http://www.cbd.int/. Accessed Mar 1999

Cullen J (2004) Wild collected material-the sine qua non of botanic garden collections? Sibbaldia 2:21-25 
Given DR (1987) What the conservationist requires of ex situ collections. In: Bramwell D, Hamann O, Heywood V, Synge H (eds) Botanic gardens and the world conservation strategy. Academic Press, London, pp 3-18

Gran Canaria Group (2006) The Gran Canaria declaration II on climate change and plant conservation. Area de Medio Ambiente y Aguas del Cabildo de Gran Canaria Jardín Botánico Canario "Viera y Clavijo" and Botanic Gardens Conservation International (BGCI). http://www.bgci.org/ourwork/gcdccpc/. Accessed Feb 2007

Hawkins B, Sharrock S, Havens K (2008) Plants and climate change: which future?. BGCI, London

Jebb MHP (2009) A Pan-European seed-list search system. www.plantnetwork.org/ebg/. Accessed 9 Jun 2009

Leadley E, Greene J (1998) The Darwin technical manual for botanic gardens. BGCI, London

Lobin W, Barthott W (1988) Sophora toromiro (Leguminosae). The lost tree of Easter Island. Botanic Gard Conserv News 1(3):32-34

Walter KS, Gillett HJ (eds) (1998) 1997 IUCN red list of threatened plants. IUCN, Gland 